Article

\title{
Occurrence and Contamination of Rare Earth Elements in Urban Mangroves of Shenzhen, South China
}

\author{
Xiaoxue Shen, Minwei Chai, Fang Yang, Ye Cao and Ruilli Li * \\ School of Environment and Energy, Peking University Shenzhen Graduate School, Shenzhen 518055, China; \\ shenxx1991@126.com (X.S.); chaimw@pkusz.edu.cn (M.C.); yangfang2013@pku.edu.cn (F.Y.); \\ cykaiyang@163.com (Y.C.) \\ * Correspondence: liruili@pkusz.edu.cn
}

Citation: Shen, X.; Chai, M.; Yang, F.; Cao, Y.; Li, R. Occurrence and

Contamination of Rare Earth

Elements in Urban Mangroves of Shenzhen, South China. Sustainability 2021, 13, 2503. https://doi.org/ $10.3390 /$ su13052503

Academic Editor: Flávio Augusto Bastos da Cruz Martins

Received: 1 February 2021

Accepted: 22 February 2021

Published: 25 February 2021

Publisher's Note: MDPI stays neutral with regard to jurisdictional claims in published maps and institutional affiliations.

Copyright: (C) 2021 by the authors Licensee MDPI, Basel, Switzerland. This article is an open access article distributed under the terms and conditions of the Creative Commons Attribution (CC BY) license (https:/ / creativecommons.org/licenses/by/ $4.0 /)$.

\begin{abstract}
Mangroves acted as sinks of terrestrial pollutants, but the occurrence and contamination of rare earth elements (REEs) in urban mangroves lacked systematic evaluation. In rapidly developing Shenzhen, China, four typical urban mangroves were selected to determine the REEs in urban mangroves, including Baguang mangrove (BGM) and Futian mangrove (FTM) featured with ecological preserve and central business district, respectively; Xixiang mangrove (XXM) and Shajing mangrove (SJM) both featured with industry district. The mean concentrations of total REEs (TREEs) in sediment (0-25 cm depth, $\left.\mu \mathrm{g} \mathrm{g}^{-1}\right)$ were SJM (465.28) > FTM (411.25) > XXM (342.76) > BGM (118.63), with Ce to be the dominant REEs element. The depositions of REEs in urban mangroves were significantly affected by sediment sulfur accumulation and fine sediment, including silt and clay fractions. The main fractionation pattern of REEs in urban mangroves was the enrichment of light REEs (LREEs) and loss of heavy REEs (HREEs). Geo-accumulation index, modified degree of contamination, pollution load index, and potential ecological risk index showed the moderately contaminated level of REEs in FTM, followed by SJM and XXM, with uncontaminated level in BGM. This study provided important information on REEs in urban mangroves for pollution prevention and remediation in the future.
\end{abstract}

Keywords: rare earth elements; contamination; urban mangrove; Shenzhen

\section{Introduction}

Rare earth elements (REEs), an element group including the lanthanide element series and yttrium, have similar physic-chemical properties and similar environmental behaviors, being extensively applied in electronic technology, medicines, agriculture, and industry around the world [1,2]. In REE resource-rich China, various kinds of products related to REEs have been produced for decades in multiple fields, including industry, agriculture, forestry, and animal husbandry [3,4]. Over the past few decades, REEs have got into the soil, water, and air with increasing exploitation and utilization of REEs-related products [5,6]. The environmental behaviors of REEs have attracted conspicuous attention, especially their geochemistry and ecotoxicity $[7,8]$. Once REEs enter the environment, they could be enriched in biota and damage human health through the food chain, resulting in various environmental and health issues [4,9].

Mangrove is an important intertidal coastal system, providing a myriad of ecological services and receives lots of terrestrial pollutants [10,11]. In mangrove sediments, REEs are relatively new pollutants, and provide insight into the elemental cycling in the coastal wetlands and the abundance of REEs in the source areas [12,13]. Wang et al. (2017) reported that the total concentrations of rare earth elements (TREEs) ranged from 141.28 to $269.20 \mathrm{mg} \mathrm{kg}^{-1}$ in mangroves in Dongzhai Harbor, Hainan Island, China [14]. Mandal et al. (2019) found that REE was an effective biological proxy to determine the degree of bioaccumulation in the mangrove of Indian Sundarban [15]. Furthermore, the ecological risk caused by REEs in the environment is increasingly receiving attention [16]. Although 
great efforts have been made to explore the distribution and geochemical characteristics of REEs in pristine mangrove sediment, the knowledge on the sedimentary records of REEs affected by anthropogenic activities and the related ecological risks is still limited, especially for urban mangroves [13-15,17,18].

In Shenzhen, one of the most urbanized cities in China, the urban mangroves can be divided into three types with different urban functions, such as Xixiang and Shajing mangroves featured with industry district; Baguang and Futian mangroves were featured with ecological preserve and central business district, respectively $[19,20]$. The background information about the REEs distribution in offshore sediments of Shenzhen was only affected by natural hydrological conditions, such as river input and ocean dilution [21]. With increasing economic development and urban construction, the urban mangroves of Shenzhen have received various pollutants (including heavy metals, POPs, and microplastics) from surrounding anthropogenic activities, without systematic report on REEs [22-25]. The objectives of this study were to: (1) quantify the deposition of REEs in sediments of urban mangroves with different urban functions in Shenzhen, China; (2) identify REE anomalies, fractionation ratios, and impacting parameters; (3) evaluate the ecological risks of REEs.

\section{Materials and Methods}

\subsection{Study Site and Sample Collection}

Shenzhen, a rapidly developing city with a dense population in southern China, is a demonstration pilot zone for socialism with Chinese characteristics. This region has a subtropical monsoonal climate, with an average annual temperature of $22{ }^{\circ} \mathrm{C}$ and rainfall of $1935.8 \mathrm{~mm}$. The average tidal range of semi-diurnal tides is $1.9 \mathrm{~m} \mathrm{[26].} \mathrm{In} \mathrm{this} \mathrm{study,}$ four types of urban mangroves were selected as follows (Figure 1): Xixiang mangrove (XXM) and Shajing mangrove (SJM) featured with industry districts, Baguang mangrove (BGM) and Futian mangrove (FTM) featured with ecological preserve and central business district (CBD), respectively. XXM and SJM were both located on the west coast of Shenzhen, and were significantly affected by input from Pearl River, with SJM to be also located in the estuarine of Maozhouhe river in Shenzhen, China. FTM, located in the Futian district of Shenzhen (northeast of Shenzhen Bay), has been well protected. As a pristine mangrove forest, FTM serves as a good indicator of surrounding anthropogenic activities, with Shenzhenhe river flowing into Shenzhen Bay. BGM, located on eastern shelf of the Dapeng district in Shenzhen, and has been protected well without significant anthropogenic activities in surrounding areas.

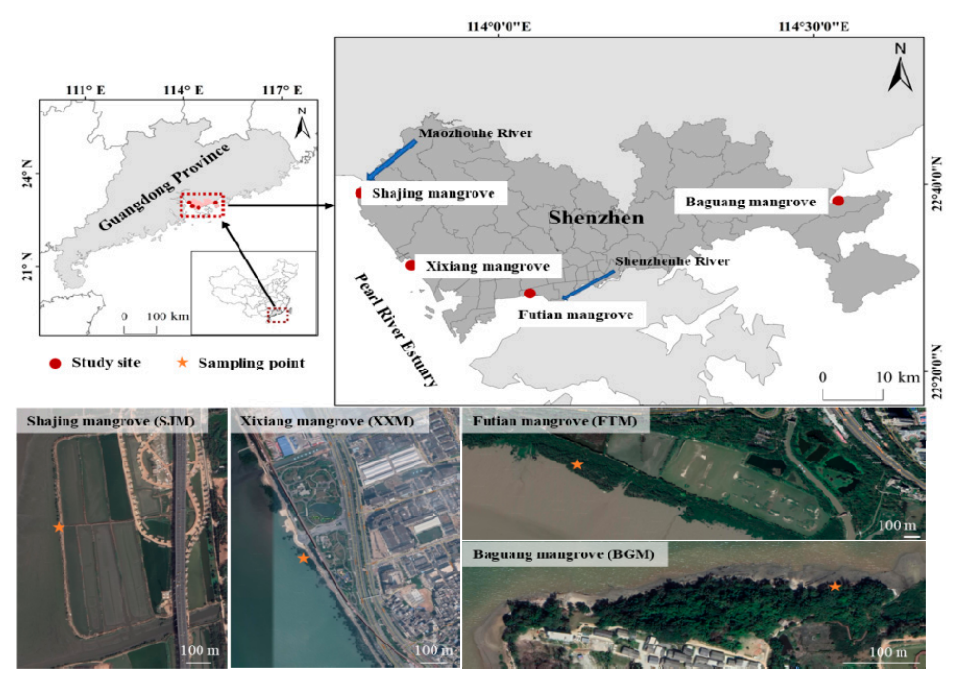

Figure 1. Study area and sample sites in urban mangroves of Shenzhen, China (www.gditu.net; accessed on 24 January 2021). 
From May 2016 to August 2017, in each urban mangrove, three sampling plots with $5 \mathrm{~m} \times 5 \mathrm{~m}$ were randomly designed with $100 \mathrm{~m}$ distance between two consecutive sampling plots. In each sampling plot, four sediments were randomly sampled at low tide. Shallow sediments ( $0-25 \mathrm{~cm}$ depth) were collected with acid-washed PVC pipes (inner diameter $7.5 \mathrm{~cm})$ in SJM, XXM, and BGM, with deep sediments $(0-88 \mathrm{~cm}$ depth) to be sampled in FTM. The shallow sediment collected in SJM, XXM, and BGM was related to plant roots and hard sediment or rocks. After removing the litter and some other debris, sediments in SJM, XXM, and BGM were separated at $5 \mathrm{~cm}$ intervals, with sediment in FTM to be separated at $8 \mathrm{~cm}$ intervals. Four sectioned subsamples at the same depth were in situ homogenized to obtain one composite sample and transferred into sample bags. Then, the sediment samples were stored in iceboxes and transported to the laboratory within the same day. Each sediment sample was divided into two parts: One was air-dried, ground, and then passed through a 60-mesh sieve (diameter $0.25 \mathrm{~mm}$ ). The other was firstly freeze-dried to a constant weight (7 days); then, pretreatments of grind, homogenization, and sifting were conducted for determination of REEs.

\subsection{Sediment Sample Analysis}

In this study, sediment $\mathrm{pH}$ and salinity were measured by $\mathrm{pH}$ meter (Sartorius $\mathrm{PB}-10$, Germany) and conductivity meter (Laboratory Benchtop Meters, China), with the sediment: water ratio to be $1: 5(w / v)$. Total organic carbon was determined by TOC analyzer (multi N/C 3100 HT 1300, Analytik Jena, Germany). For particle size analysis, a laser particle size analyzer was used (Master 2000, Malvern Co., USA), with the classification of particle sizes to be clay $(0-4 \mu \mathrm{m})$, silt $(4-25 \mu \mathrm{m})$, and sand $(25-2000 \mu \mathrm{m})$. The analysis of REEs was referred to the analysis method of Chinese National Standard GB/T14506.30-2020 (GB/T 14506.30-2010). The air-dried samples were powdered and digested in a microwave furnace using an $\mathrm{HF}+\mathrm{HNO}_{3}$ mixture in Teflon vessels at $185^{\circ} \mathrm{C}$ for $24 \mathrm{~h}$, and then determined by high resolution inductively coupled plasma mass spectrometer (ELEMENT XR, USA). In this study, all reagents used were guaranteed reagents or better, and the analytical error of REE determination was controlled within $5 \%$.

Generally speaking, REEs can be divided into light REE (LREE: La, Ce, Pr, and Nd), middle REE (MREE: Sm, Eu, Gd, Tb, Dy, and Ho), and heavy REE (HREE: Er, Tm, Yb, and $\mathrm{Lu}$ ) based on atomic and radius [27]. In this study, Post-Archean Australian Shale (PAAS) standard was used to normalize REE concentration [28]. The ratio of LREE to

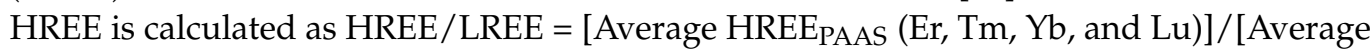
LREE $_{\text {PAAS }}$ (La, Ce, Pr, and Nd)]. The degree of MREE enrichment is quantified as MREE enrichment $=$ Average MREE $_{\text {PAAS }} /$ Average $\left(\right.$ HREE $_{\text {PAAS }}$ and LREE PAAS $)$. The anomalies in REE pattern are calculated by the ratio of the normalized concentration to the geogenic background concentration. In this study, the anomalies of $\mathrm{Ce}, \mathrm{Eu}$, and $\mathrm{Gd}$ are obtained as follows [29]:

$$
\begin{aligned}
& \mathrm{Ce}_{\text {anomaly }}=\mathrm{Ce}_{\mathrm{PAAS}} / \mathrm{Ce}_{\mathrm{PAAS}}{ }^{*}, \mathrm{Ce}_{\mathrm{PAAS}}{ }^{*}=\left(\mathrm{La} \text { PAAS }+\operatorname{Pr}_{\mathrm{PAAS}}\right) / 2 \\
& \mathrm{Eu}_{\text {anomaly }}=\mathrm{Eu}_{\mathrm{PAAS}} / \mathrm{Eu}_{\mathrm{PAAS}}{ }^{*}, \mathrm{Eu}_{\mathrm{PAAS}}{ }^{*}=\left(\mathrm{Sm}_{\mathrm{PAAS}}+\mathrm{Tb}_{\mathrm{PAAS}}\right) / 2 \\
& \mathrm{Gd}_{\text {anomaly }}=\mathrm{Gd}_{\text {PAAS }} / \mathrm{Gd}_{\text {PAAS }} * \mathrm{Gd}_{\text {PAAS }} *=\left(\mathrm{Nd}_{\text {PAAS }}+\text { DyPAAS }\right) / 2
\end{aligned}
$$

where Ce $e_{\text {PAAS }}$ is the measured Ce concentrations normalized to PAAS [28]; the geogenic background $\mathrm{Ce}_{\text {PAAS }}{ }^{*}$ concentration is interpolated from La and Pr; the geogenic background $\mathrm{Eu}_{\text {PAAS }}{ }^{*}$ concentration is interpolated from $\mathrm{Sm}$ and $\mathrm{Tb} ; \mathrm{Nd}$ and $\mathrm{Dy}$ is used to interpolate Gd PAAS $^{*}$. Positive anomalies are defined as calculated values that are $>1$, with negative anomalies to be $<1$.

The measured concentration of Gd is composed of natural Gd and anthropogenic Gd, and the anthropogenic $\mathrm{Gd}$ can be calculated as follows [30]:

$$
\mathrm{Gd}_{\text {anthropogenic }}=\mathrm{Gd}_{\text {measured }}-\mathrm{Gd}_{\text {natural }}, \mathrm{Gd}_{\text {natural }}=\mathrm{Gd}_{\mathrm{PAAS}} \times \mathrm{Gd}(\mathrm{PAAS})
$$


where $\mathrm{Gd}_{\mathrm{PAAS}}{ }^{*}$ is geogenic Gd concentration interpolated between $\mathrm{Nd}$ and $\mathrm{Dy}$. Gd(PAAS) is Gd concentration in the PAAS $\left(4.7 \mathrm{mg}^{-1} \mathrm{~kg}\right)$, which is commonly used for normalization [28].

\subsection{Pollution and Ecological Risk of REEs in Sediments}

In this study, four evaluation methods including geo-accumulation index $\left(I_{g e o}\right)$, modified degree of contamination $\left(\mathrm{mC}_{\mathrm{d}}\right)$, pollution load index (PLI), and potential ecological risk index (PERI) were selected in evaluating pollution of REEs in mangrove sediments [31-34]. The background concentrations of REEs in soils of China were used for calculating $I_{g e o}$, $m C_{d}$, and PLI [35]. The formulae of these indices were as follows:

$$
\begin{gathered}
\mathrm{I}_{\text {geo }}=\log _{2} \frac{C_{m}^{i}}{C_{b}^{i}} \\
m C_{d}=\frac{\sum_{i=1}^{n} \frac{C_{m}^{i}}{C_{b}^{i}}}{n} \\
\text { PLI }=\left(\frac{C_{m}^{1}}{C_{b}^{1}} \times \frac{C_{m}^{2}}{C_{b}^{2}} \times \ldots \times \frac{C_{m}^{n}}{C_{b}^{n}}\right)^{\frac{1}{n}} \\
\text { PERI }=\sum_{i=1}^{n} T_{m}^{i} \times \frac{C_{m}^{i}}{C_{b}^{i}}
\end{gathered}
$$

where $C_{m}^{i}$ and $C_{b}^{i}$ are the measured content and background level of the REEs in sediments, respectively; $\mathrm{n}$ is the number of the studied REEs elements. $T_{m}^{i}$ is the toxic factor of studied REEs. The toxic factors for REEs referred to Wang et al. (2020), with $T_{m}^{i}$ values of $\mathrm{La}, \mathrm{Ce}, \mathrm{Pr}$, $\mathrm{Nd}, \mathrm{Sm}, \mathrm{Eu}, \mathrm{Gd}, \mathrm{Tb}, \mathrm{Dy}, \mathrm{Ho}, \mathrm{Er}, \mathrm{Tm}, \mathrm{Yb}, \mathrm{Lu}$, and $\mathrm{Y}$ to be 1, 1, 5, 2, 5, 10, 5, 10, 5, 10, 5, 10, 5,20 , and 2, respectively [36]. The classifications of four pollution indices were shown in Table S1 [32,37-39].

\section{Results and Discussion}

\subsection{Physicochemical Properties of Sediment in Urban Mangroves}

The geochemical parameters ( $\mathrm{pH}$, salinity, TOC, Total $\mathrm{S}$, and grain size characteristics) in sediments $(0-25 \mathrm{~cm}$ depth) from different urban mangroves were summarized in Table 1. Briefly, the sediment was acidic, with mean values of $\mathrm{pH}$ in urban mangroves to be SJM (5.76) < BGM (6.42) < FTM (6.71) < XXM (6.87). Generally speaking, the lower $\mathrm{pH}$ values in mangrove sediments were mainly because of mangrove litter deposition and tannin hydrolysis. Furthermore, the lowest $\mathrm{pH}$ in SJM (5.76) may be attributed to its adjacent to the estuary of Maozhou river, which directly accepts the industrial and domestic sewage from nearby regions and is seriously polluted [40]. The salinity ranged from $2.07 \%$ to $3.62 \%$ in urban mangrove sediments, with the highest salinity in BGM (3.62\%), which may be due to no dilution from rivers in BGM, being different from that of the other urban mangroves, such as Shenzhenhe river and Maozhouhe river in Shenzhen, as well as Pearl River in South China. The higher levels of TOC (3.53\%) and Total S (1.63\%) detected in FTM may be caused by the autochthonous deposition (including accumulation of mangrove litter) and allochthonous detrital matter supplied by terrigenous discharge, especially from Shenzhenhe River [41,42]. In terms of the grain size distribution, sediments in XXM and SJM were mainly composed of fine fractions (clay+silt) $(77.29 \%$ and $76.76 \%)$, followed by FTM $(53.59 \%)$ and BGM $(43.48 \%)$. In addition, the mean level of total S in FTM was $1.63 \%$, being higher than that of BGM $(0.71 \%)$, XXM $(0.88 \%)$, and SJM $(0.89 \%)$. 
Table 1. Physicochemical properties of sediment (0-25 cm depth) in urban mangroves of Shenzhen, China.

\begin{tabular}{cccccccc}
\hline \multirow{2}{*}{ Sites } & \multicolumn{7}{c}{ Mean \pm S.D. (Min-Max) } \\
\cline { 2 - 8 } & $\mathbf{p H}$ & Salinity (\%) & TOC (\%) & Total S (\%) & Clay (\%) & Silt (\%) & Sand (\%) \\
\hline \multirow{2}{*}{ BGM } & $6.42 \pm 0.26$ & $3.62 \pm 1.13$ & $2.30 \pm 1.14$ & $0.71 \pm 0.16$ & $4.26 \pm 1.37$ & $39.22 \pm 8.66$ & $56.52 \pm 9.87$ \\
& $(6.15-6.78)$ & $(2.23-4.90)$ & $(0.88-3.53)$ & $(0.47-0.87)$ & $(2.62-5.89)$ & $(31.53-50.61)$ & $(43.50-65.84)$ \\
& $6.71 \pm 0.10$ & $2.07 \pm 0.32$ & $3.53 \pm 0.40$ & $1.63 \pm 0.23$ & $9.70 \pm 2.48$ & $43.89 \pm 5.68$ & $46.41 \pm 7.94$ \\
FTM & $(6.56-6.82)$ & $(1.67-2.49)$ & $(3.15-3.94)$ & $(1.43-1.88)$ & $(6.03-12.25)$ & $(35.36-50.32)$ & $(37.43-58.61)$ \\
& $6.87 \pm 0.35$ & $2.67 \pm 0.94$ & $2.13 \pm 0.79$ & $0.88 \pm 0.34$ & $16.62 \pm 5.42$ & $45.01 \pm 9.82$ & $22.71 \pm 4.53$ \\
XXM & $(6.48-7.39)$ & $(1.20-4.70)$ & $(1.29-3.58)$ & $(0.45-1.46)$ & $(10.44-30.22)$ & $(28.73-58.02)$ & $(12.98-28.36)$ \\
& $5.76 \pm 0.08$ & $2.53 \pm 0.52$ & $2.43 \pm 0.23$ & $0.89 \pm 0.15$ & $13.37 \pm 3.65$ & $63.38 \pm 8.45$ & $23.24 \pm 12.06$ \\
SJM & $(5.69-5.89)$ & $(2.02-3.09)$ & $(2.07-2.63)$ & $(0.73-1.05)$ & $(8.40-17.81)$ & $(51.10-71.56)$ & $(10.63-40.49)$ \\
\hline
\end{tabular}

Note: The depth of $0-24 \mathrm{~cm}$ in FTM was used in this table. BGM, Baguang mangrove; FTM, Futian mangrove; XXM, Xixiang mangrove; SJM, Shajing mangrove.

\subsection{Distributions of REEs in Urban Mangrove Sediments}

In Table 2, the mean concentrations of TREEs in sediments $(0-25 \mathrm{~cm}$ depth) of urban mangroves were SJM $\left(465.28 \mu \mathrm{g} \mathrm{g}^{-1}\right)>$ FTM $\left(411.25 \mu \mathrm{g} \mathrm{g}^{-1}\right)>$ XXM $\left(342.76 \mu \mathrm{g} \mathrm{g}^{-1}\right)>\mathrm{BGM}$ $\left(118.63 \mu \mathrm{g} \mathrm{g}^{-1}\right)$, with the trend to be similar to some other pollutants reported in the same urban mangroves, such as heavy metals and polybrominated diphenyl ethers $[23,24,43]$. Furthermore, RREs were mainly composed of $\mathrm{Ce}, \mathrm{La}, \mathrm{Nd}$, and $\mathrm{Y}$, with Ce to be the most abundant REEs in all urban mangroves. In view of the similar compositions of REEs reported in mangrove sediments, the concentrations of TREEs in FTM, XXM, and SJM were higher than that in some other places, such as mangroves $\left(189.26 \mathrm{\mu g} \mathrm{g}^{-1}\right)$ in Pichavaram [44], mangroves (140-159 $\mathrm{g} \mathrm{g}^{-1}$ ) in Indian Sundarban [15], and mangroves (202-220 $\mu \mathrm{g} \mathrm{g}^{-1}$ ) in Jaguaripe estuary [13]. Furthermore, the concentrations of TREEs in FTM, XXM, and SJM were higher than the Earth's crust $\left(153.80 \mu \mathrm{g} \mathrm{g}^{-1}\right)$ [45] and plant food in China $\left(0.5-2 \mu \mathrm{g} \mathrm{g}^{-1}\right)$ (GB13107-91). Generally speaking, REEs are important accompanying elements in phosphate fertilizers, with fertilizer spill would contribute to the REEs deposition in mangroves [46]. Furthermore, in this study, different depositions of REEs in sediments of urban mangroves were expected to be related to their specific hydrographic features $[23,24]$. For example, XXM and SJM are located on the west coast of Shenzhen (east coast of the Pearl River estuary), and directly obtain the input from the upstream of Pearl River, with SJM being also affected by pollution from Maozhouhe river from Shenzhen; FTM is located in semi-closed Shenzhen Bay with low water exchange capacity, and received matter deposition from Shenzhenhe river, which would improve the deposition of REE in sediment; BGM is located on the east coast of Shenzhen without significant anthropogenic activities, and is only affected by dilution of ocean tides.

Generally speaking, the distribution of REEs in sediment cores records the historical changes of REE deposition [13,47]. As for deposition of individual REEs in urban mangrove sediments (Table S2), the main composition of REEs (including $\mathrm{Ce}, \mathrm{La}, \mathrm{Nd}$, and $\mathrm{Y}$ ) demonstrated reducing trends with increasing depth, except for $\mathrm{Y}$ in XXM, and $\mathrm{Nd}$ and $\mathrm{Y}$ in SJM. Similarly, the reducing trends of heavy metals [23,24,43] and microplastics [25] were also reported in urban mangroves in Shenzhen, China, indicating their similar geochemical properties or pollution sources.

Sediment texture is important in affecting the deposition of REEs in sediment, and the total concentrations of REEs are positively correlated with the percentage of fine particles, that is, a higher fine-grain percentage coexists with higher REEs accumulations [13,15]. In this study, the sediments in FTM, XXM, and SJM were mainly composed of fine particles (including clay and silt), with percentages ranging from $53.59 \%$ to $77.29 \%$ (Table 1 ). In all urban mangroves, clay percentages were positively correlated with all REE elements, while silt percentages were positively correlated with four REEs ( $\mathrm{La}, \mathrm{Ce}, \mathrm{Pr}$, and $\mathrm{Eu}$ ), and no positive correlations were detected among sand and REEs (Table 3). In particular, BGM was far away from the anthropogenic sources of contaminants and the sediments were relatively coarser with a high percentage of sand fraction, which reduced REE deposition. 
Table 2. The concentrations of rare earth elements in urban mangrove sediments $\left(0-25 \mathrm{~cm} \mathrm{depth,} \mu \mathrm{g} \mathrm{g}{ }^{-1}\right)$ of Shenzhen, China.

\begin{tabular}{|c|c|c|c|c|c|c|c|c|c|c|c|c|c|c|c|c|c|}
\hline Sites & & La & $\mathrm{Ce}$ & Pr & Nd & $\mathrm{Sm}$ & $\mathrm{Eu}$ & Gd & $\mathrm{Tb}$ & Dy & Ho & Er & $\mathrm{Tm}$ & $\mathrm{Yb}$ & Lu & $Y$ & TREES \\
\hline \multirow[t]{4}{*}{ BGM } & Mean & 22.12 & 49.16 & 4.74 & 17.48 & 3.25 & 0.51 & 2.61 & 0.44 & 2.40 & 0.43 & 1.27 & 0.23 & 1.39 & 0.20 & 12.40 & 118.63 \\
\hline & Min & 14.60 & 34.80 & 3.14 & 11.30 & 2.12 & 0.38 & 1.74 & 0.30 & 1.63 & 0.29 & 0.90 & 0.16 & 0.99 & 0.14 & 7.89 & 80.38 \\
\hline & Median & 23.10 & 50.10 & 4.80 & 18.70 & 3.41 & 0.52 & 2.72 & 0.45 & 2.49 & 0.46 & 1.30 & 0.24 & 1.42 & 0.20 & 12.70 & 124.77 \\
\hline & $\mathrm{CV}(\%)$ & 22.44 & 18.65 & 21.92 & 22.14 & 21.54 & 17.09 & 21.89 & 19.47 & 19.26 & 19.30 & 17.96 & 17.22 & 17.36 & 17.81 & 21.89 & 20.07 \\
\hline \multirow[t]{4}{*}{ FTM } & Mean & 80.93 & 144.33 & 18.07 & 64.87 & 12.57 & 1.80 & 10.40 & 1.81 & 9.98 & 1.78 & 5.01 & 0.85 & 5.00 & 0.70 & 53.17 & 411.25 \\
\hline & Min & 78.60 & 141.00 & 17.40 & 63.90 & 12.30 & 1.77 & 10.30 & 1.79 & 9.65 & 1.75 & 4.88 & 0.83 & 4.84 & 0.68 & 52.00 & 401.80 \\
\hline & Median & 81.60 & 143.00 & 17.80 & 64.50 & 12.50 & 1.78 & 10.40 & 1.81 & 9.98 & 1.78 & 4.97 & 0.85 & 5.01 & 0.69 & 53.70 & 410.27 \\
\hline & CV $(\%)$ & 2.57 & 2.88 & 4.61 & 1.84 & 2.43 & 2.74 & 0.96 & 1.10 & 3.26 & 1.69 & 2.96 & 2.19 & 3.01 & 2.55 & 1.90 & 2.43 \\
\hline \multirow[t]{5}{*}{ XXM } & Mean & 67.81 & 140.60 & 14.14 & $\begin{array}{l}1.07 \\
48.13\end{array}$ & 9.16 & 1.49 & 7.81 & 1.33 & 7.18 & 1.29 & 3.60 & 0.62 & 3.64 & 0.52 & 35.45 & 342.76 \\
\hline & Min & 55.40 & 119.00 & 11.90 & 36.90 & 6.81 & 1.08 & 5.85 & 1.00 & 5.09 & 0.91 & 2.55 & 0.46 & 2.74 & 0.38 & 24.80 & 282.86 \\
\hline & Median & 63.50 & 127.00 & 14.30 & 49.55 & 9.31 & 1.52 & 8.37 & 1.37 & 7.33 & 1.30 & 3.63 & 0.63 & 3.62 & 0.52 & 36.40 & 340.01 \\
\hline & Max & 104.00 & 228.00 & 17.10 & 54.90 & 10.60 & 1.78 & 8.83 & 1.60 & 8.67 & 1.57 & 4.41 & 0.78 & 4.49 & 0.63 & 43.70 & 469.15 \\
\hline & CV $(\%)$ & 21.78 & 24.36 & 11.66 & 14.02 & 15.04 & 16.38 & 13.80 & 16.55 & 17.48 & 19.00 & 18.70 & 18.92 & 18.20 & 18.22 & 19.18 & 16.53 \\
\hline \multirow[t]{3}{*}{ SJM } & Mean & 102.20 & 212.00 & 16.42 & 54.90 & 10.25 & 1.76 & 9.52 & 1.46 & 7.91 & 1.38 & 3.90 & 0.66 & 3.96 & 0.56 & 38.40 & 465.28 \\
\hline & Min & 87.30 & 177.00 & 15.80 & 53.00 & 9.96 & 1.69 & 9.07 & 1.42 & 7.66 & 1.33 & 3.77 & 0.63 & 3.81 & 0.55 & 36.50 & 417.64 \\
\hline & Median & 102.00 & 216.00 & 16.40 & 54.70 & 10.20 & 1.76 & 9.60 & 1.43 & 7.94 & 1.39 & 3.80 & 0.67 & 3.97 & 0.56 & 38.90 & 464.96 \\
\hline
\end{tabular}

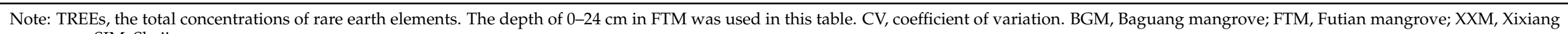
mangrove; SJM, Shajing mangrove.

Table 3. Correlations between sediment physicochemical properties and rare earth elements in urban mangroves (0-25 cm depth) of Shenzhen, China.

\begin{tabular}{|c|c|c|c|c|c|c|c|c|c|c|c|c|c|c|c|}
\hline & $\mathrm{La}$ & $\mathrm{Ce}$ & $\operatorname{Pr}$ & $\mathrm{Nd}$ & $\mathrm{Sm}$ & $\overline{E u}$ & Gd & $\mathrm{Tb}$ & Dy & Ho & $\mathrm{Er}$ & $\mathrm{Tm}$ & $\mathrm{Yb}$ & Lu & $\bar{Y}$ \\
\hline $\mathrm{pH}$ & -0.25 & -0.25 & -0.05 & -0.09 & -0.07 & -0.17 & -0.13 & -0.06 & -0.06 & -0.05 & -0.06 & -0.05 & -0.06 & -0.06 & -0.02 \\
\hline Salinity & $-0.52 *$ & $-0.47^{*}$ & $-0.53 *$ & $-0.54 *$ & $-0.56 *$ & -0.56 * & $-0.55 *$ & $-0.55^{*}$ & $-0.57 *$ & $-0.57^{*}$ & $-0.57^{*}$ & $-0.56^{*}$ & $-0.56^{*}$ & $-0.56^{*}$ & $-0.55 *$ \\
\hline TOC\% & 0.28 & 0.19 & 0.39 & 0.43 & 0.45 & 0.36 & 0.40 & 0.43 & 0.44 & 0.45 & 0.45 & 0.44 & 0.44 & 0.43 & $0.49 *$ \\
\hline Clay & $0.65^{* *}$ & $0.67^{* *}$ & $0.67^{* *}$ & $0.60^{* *}$ & $0.59 *$ & $0.67^{* *}$ & $0.64^{* *}$ & $0.60^{* *}$ & 0.59 * & $0.58 *$ & $0.57 *$ & 0.58 * & 0.57 * & 0.58 * & 0.51 * \\
\hline Silt & $0.55^{*}$ & $0.63^{* *}$ & $0.50 *$ & 0.39 & 0.37 & $0.47^{*}$ & 0.44 & 0.38 & 0.36 & 0.35 & 0.34 & 0.36 & 0.34 & 0.36 & 0.28 \\
\hline Sand & -0.58 * & $-0.65^{* *}$ & $-0.55 *$ & -0.45 & -0.42 & -0.53 * & $-0.49 *$ & -0.44 & -0.42 & -0.41 & -0.40 & -0.42 & -0.40 & -0.42 & -0.34 \\
\hline
\end{tabular}


Generally speaking, REEs are correlated with organic matter in wetland soil solution or shallow groundwater, and different kinds of groups in organic matter have different function sites to combine with REEs [48]. In mangrove sediments, the organic matter (OM) acts as an important binding phase in adsorbing and depositing REEs [49]. However, in all urban mangroves, no positive correlations were detected for TOC and all REEs (Table 3). Thus, the role of OM in the deposition of REEs in urban mangrove sediment was limited. On the other hand, the total $S$ was positively correlated with most REEs in urban mangrove sediment, except for La, Ce, and Lu (Table 3). Previous studies have found that sulfide had the potential to carry REEs in natural systems [50,51]. Thus, sulfide was expected to play an important role in REEs mobility in urban mangrove sediments with reducing and anaerobic sedimentary environments.

\subsection{Characteristic Parameter of REEs}

After standardizing the mass fraction of REEs based on the Post-Archean Australian Shale (PAAS), the standardized distribution patterns of REEs in urban mangrove sediments of Shenzhen, China were shown in Figure 2. The distribution curves of REEs in XXM and SJM were all around or greater than 1, with 0-48 cm depth sediment in FTM being greater than 1; while that of BGM is less than 1. Generally speaking, REEs would release and leach under anaerobic conditions [52]. Without exogenous input, the abundance of REE in mangrove sediment was relatively low under periodic tide flooding [14,17]. In this study, the amount of REEs in BGM featured with ecological preserve demonstrated loss of REE, while FTM, XXM, and SJM were significantly affected by input from anthropogenic activities, with REEs to be enriched. Furthermore, compared with BGM and FTM, the distribution curves of REEs in XXM and SJM demonstrated significant negative slope mode inclining gently to the right (Figure 2), demonstrating LREE enrichment and HREE loss.

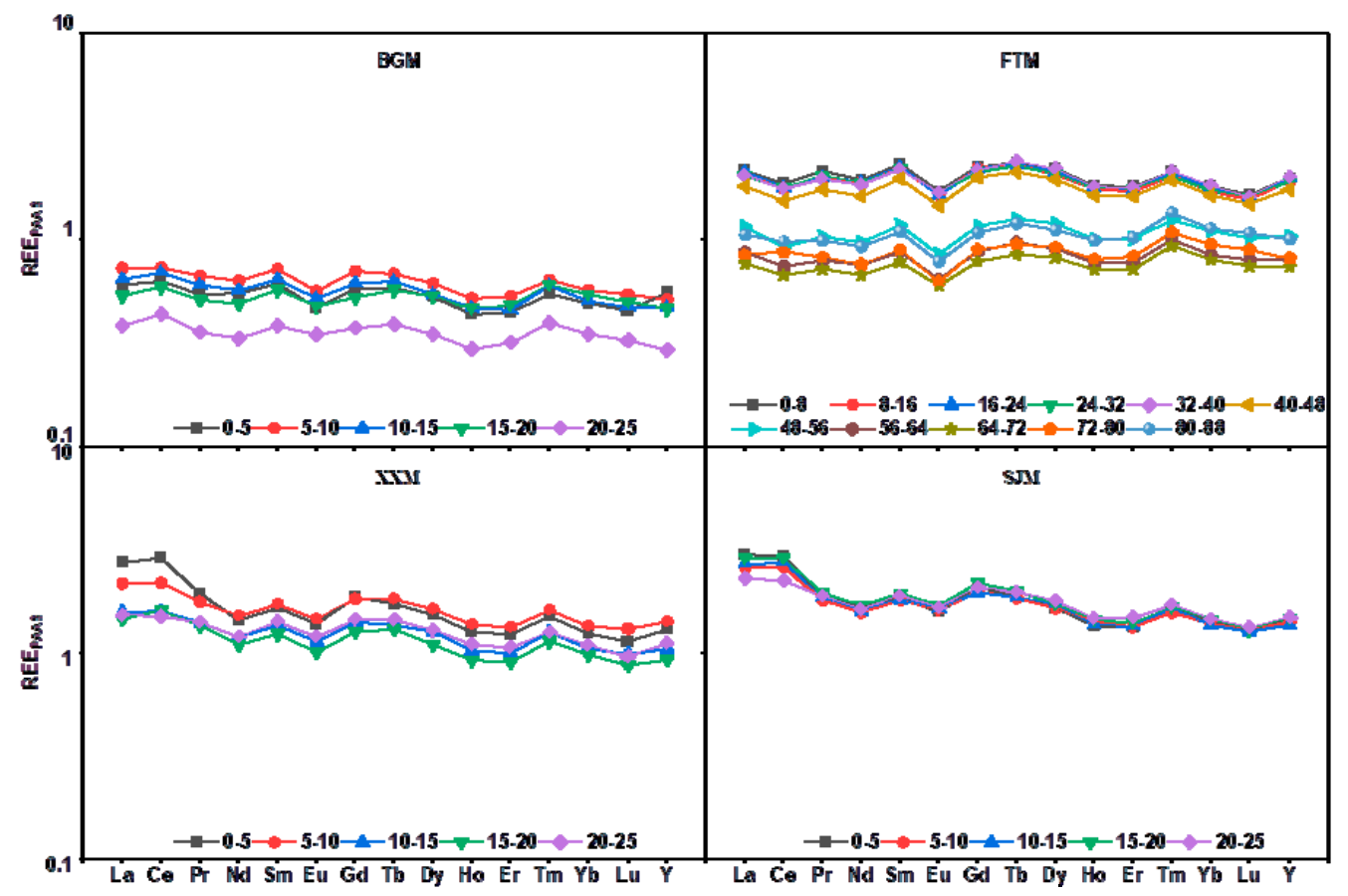

Figure 2. Post-Archean Australian Shale (PAAS)-normalized rare earth element distributions at different depths $(\mathrm{cm})$ in urban mangroves in Shenzhen, China. The PAAS-normalized data was plotted on a log scale. BGM, Baguang mangrove; FTM, Futian mangrove; XXM, Xixiang mangrove; SJM, Shajing mangrove.

In this study, the REEs fractionation patterns were explored in sediments of urban mangroves (Table 4). The HREE/LREE ratios in all urban mangroves were lower than 1 (ranging from 0.65 in SJM to 0.92 in FTM), which demonstrated enrichment of LREE in 
urban mangrove sediments. While the MREE enrichment values slightly fluctuated across 1 (ranging from 0.97 in SJM to 1.10 in FTM), which indicated no significant enrichment or loss of MREE fraction.

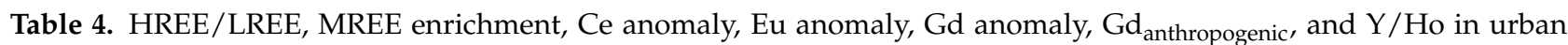
mangrove sediments (0-25 cm depth) of Shenzhen, China.

\begin{tabular}{|c|c|c|c|c|c|c|c|}
\hline & $(\text { HREE/LREE) })_{\text {PAAS }}$ & $\begin{array}{c}\text { ¿MREE PAAS } \\
\text { Enrichment }\end{array}$ & $\begin{array}{c}\text { CepaAs } \\
\text { Anomaly }\end{array}$ & $\begin{array}{c}\text { EupAAS } \\
\text { Anomaly }\end{array}$ & $\begin{array}{l}\text { GdPAAS } \\
\text { Anomaly }\end{array}$ & Gd $_{\text {anthropogenic }}$ & $\mathrm{Y} / \mathrm{Ho}_{\text {weight }}$ \\
\hline BGM & $0.88 \pm 0.08$ & $1.00 \pm 0.01$ & $1.12 \pm 0.05$ & $0.83 \pm 0.5$ & $1.09 \pm 0.04$ & $0.21 \pm 0.11$ & $28.66 \pm 3.44$ \\
\hline FTM & $0.92 \pm 0.00$ & $1.10 \pm 0.01$ & $0.87 \pm 0.01$ & $0.73 \pm 0.01$ & $1.10 \pm 0.02$ & $0.97 \pm 0.20$ & $29.87 \pm 0.26$ \\
\hline XXM & $0.81 \pm 0.14$ & $1.04 \pm 0.08$ & $1.04 \pm 0.10$ & $0.82 \pm 0.02$ & $1.14 \pm 0.05$ & $0.93 \pm 0.34$ & $27.53 \pm 0.55$ \\
\hline SJM & $0.65 \pm 0.06$ & $0.97 \pm 0.04$ & $1.17 \pm 0.06$ & $0.87 \pm 0.02$ & $1.23 \pm 0.04$ & $1.81 \pm 0.30$ & $27.76 \pm 0.87$ \\
\hline
\end{tabular}

HREE, heavy REE; MREE, middle REE; LREE, light REE. Values below 1 suggest LREE enrichment over HREE, MREE depletion over HREE and LREE, negative Ce anomaly, negative Eu anomaly, and negative Gd anomaly, respectively. The values above 1 suggest the opposite result to values below 1. The Y/Ho ratio of PAAS data (the Post-Archean Australian shale) was 27. BGM, Baguang mangrove; FTM, Futian mangrove; XXM, Xixiang mangrove; SJM, Shajing mangrove.

Generally speaking, anomalies of $\mathrm{Ce}$ and Eu reflect the characteristics of the depositional environment. The redox-sensitive $\mathrm{Ce}$ and Eu could indicate the changes of redox conditions in sediments [53]. In the reduced sediment of Zhangjiang estuary, Ce demonstrated little variation from 0.98 to 1.03 [54]. In this study, Ce PAAS anomalies have significant negative relationships with TOC and TS (Table S3, $P<0.05$ ). The negative Ce PAAS anomaly in FTM (0.87) indicated significant scavenging of Ce and dissolution of insoluble Ce (IV) to soluble Ce (III) due to the reducing environment, which would cause the depletion of Ce in FTM. However, the positive CePAAS anomalies in XXM, SJM, and BGM, indicated the limited scavenging function of organic matter [55], due to their lower TOC and Total S levels compared to FTM (Table 1). The higher TOC and Total S contents in the sediment would further aggravate the reducing conditions. Furthermore, the positive $\mathrm{Ce}$ anomalies in reducing sediments may be related to newly precipitated $\mathrm{Mn}$ and Fe oxides/hydroxides which would preferentially incorporated Ce compared to the other REEs [29]. In this study, the negative EuPAAS anomalies in urban mangroves may also be related to the deficit of Eu in the source of sediment, with anomalies of Eu in sediments of Shenzhen Bay and Dapeng Bay of China to be 0.46 and 0.86 [21]. Furthermore, in the granites from South Chinese deposits, REE minerals also show negative Eu anomaly [56]. The higher $\mathrm{Gd}_{\text {PAAS }}$ anomaly of 1.23 in SJM also showed a contribution of $\mathrm{Gd}$ from non-geogenic, likely anthropogenic sources (higher $\mathrm{Gd}_{\text {anthropogenic }}$ of 1.18 in SJM). This result was consistent with $\mathrm{Xu}$ et al. (2018) reported the anthropogenic source (with positive Gd anomalies) in estuarine sediments in South Yunderup, Australia [29]. Generally speaking, yttrium (Y) and holmium (Ho) have identical valences and similar ionic radius, with $\mathrm{Y} / \mathrm{Ho}$ ratio to be used for indicating terrestrial contribution [29,57]. In this study, the $\mathrm{Y} / \mathrm{Ho}$ ratios in urban mangroves (ranging from 27.53 in XXM to 29.87 in FTM) were generally in agreement with previous terrestrial $Y$ /Ho values (27.0-32.9) [58], demonstrating the significant contribution of terrestrial detritus.

\subsection{Pollution and Ecological Risk of REEs}

REEs could enter in soil and water and bioaccumulate through the food chain, having similar characteristics with heavy metal pollutants, including persistence, bioaccumulation, and chronic toxicity $[59,60]$. In this study, four evaluation methods including $I_{g e o}, \mathrm{mC}_{\mathrm{d}}$, PLI, and PERI were used to explore the pollution and ecological risk of REEs (Figure 3). $I_{g e o}$ is mainly used to assess the pollution intensity of individual REE elements. In view of the evaluation criterion of $I_{\text {geo }}$ (Table S1), the risk caused by REEs mainly belonged to uncontaminated/uncontaminated to moderately contaminated level, except for the moderately contaminated level of Ce in SJM (Figure 3A). Furthermore, Igeo values of REEs in urban mangroves featured with different urban functions showed remarkable site-specific features, with the values of $I_{g e o}$ of REEs to be FTM, SJM $>$ XXM $>$ BGM. The 
values of $\mathrm{mC}_{\mathrm{d}}$, PLI, and PERI of REEs in BGM were all lower than that of FTM, SJM, and XXM (Figure $3 \mathrm{~B}, \mathrm{C}, \mathrm{D}$ ). In addition, the distribution of $\mathrm{mC}_{\mathrm{d}}$ values of REEs in urban mangroves was different from that of PLI and PERI, which may be related to the different calculation and pollution evaluation criteria $[37,39] . \mathrm{mC}_{\mathrm{d}}$ is a comprehensive index in evaluating soil pollution degree. In the light of $\mathrm{mC}_{\mathrm{d}}$ criterion (Table S1), REEs in BGM was uncontaminated to a very low contaminated level, with SJM to be low contaminated, and FTM and XXM to be moderately contaminated. PLI mainly showed comparative information in assessing the pollution of REEs [33]. Based on the criterion of PLI (Table S1), REEs in BGM were uncontaminated, with XXM and SJM to be slightly contaminated, and FTM to be moderately contaminated. Similarly, according to the criterion of PERI (Table S1), a low risk of REEs was detected in BGM, with moderate risks in FTM, XXM, and SJM. In particular, the main contributors to ecological risks of REEs were not obvious, being similar to that of $I_{g e o}$ evaluation. Although pollution posed by individual REEs seemed not serious, the TREEs would still incur non-negligible pollution and ecological risks during long time exposure due to their non-biodegradability and bioaccumulation. In the future, more research work should be systematically conducted on the health risk evaluation of REEs deposited in urban mangroves, especially for susceptible groups in coastal regions, including infants, pregnant women, and the elderly. As for the remediation of REEs in urban mangroves in Shenzhen, systematic work should be conducted, such as restoration of mining areas in upstream of Pearl River in South China, reduction of the discharge and enhanced recycle use of REEs-related electronic product in Shenzhen. Furthermore, long-term monitoring and protection of urban mangroves are necessary for remediation of REEs pollution in urban mangroves of Shenzhen, China.
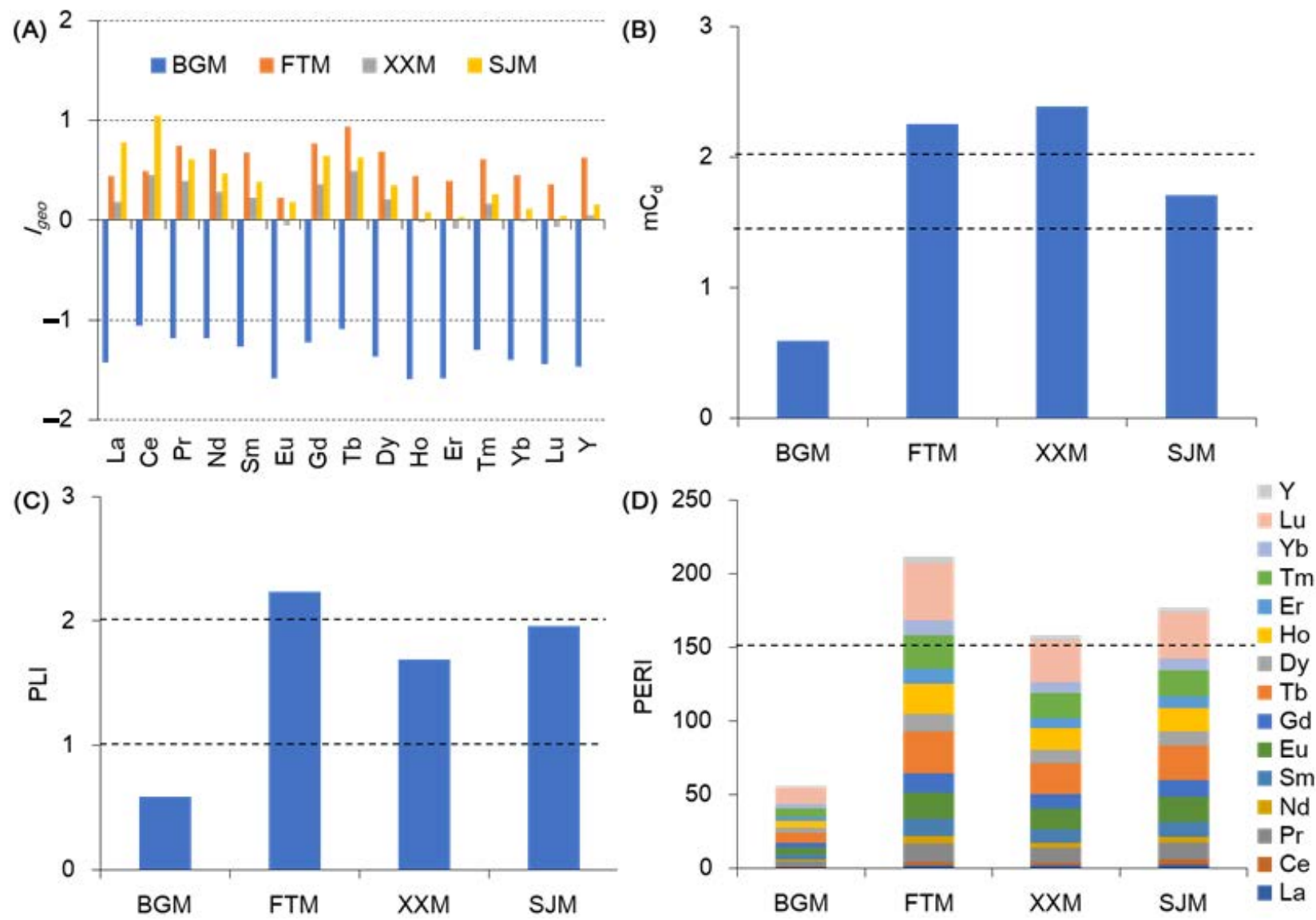

Figure 3. Geo-accumulation indexes $\left(I_{g e o}\right)(\mathbf{A})$, modified contamination degree $\left(\mathrm{mC}_{\mathrm{d}}\right)(\mathbf{B})$, pollution load index (PLI) (C), and potential ecological risk index (PERI) (D) of rare earth elements in urban mangrove sediments $(0-25 \mathrm{~cm}$ depth) of Shenzhen, China. BGM, Baguang mangrove; FTM, Futian mangrove; XXM, Xixiang mangrove; SJM, Shajing mangrove. 


\section{Conclusions}

In rapidly developing Shenzhen, China, four typical urban mangroves were selected to explore the contamination caused by REEs, including BGM featured with the ecological preserve, FTM featured with CBD, and SJM and XXM featured with industry district. The concentrations of TREEs in urban mangrove sediments ranged as SJM $>$ FTM $>$ XXM $>$ BGM, with the dominant compositions of REEs to be Ce. In urban mangrove sediments, fine sediment and sulfur deposition play important roles in the deposition of REEs. Furthermore, REEs demonstrated significant LREE enrichment and HREE loss. Although the ecological risks of REEs in urban mangroves were not higher than moderately contaminated level, research work on pollution prevention and remediation should be performed due to their non-biodegradability, persistence, and bioaccumulation in the environment.

Supplementary Materials: The following are available online at https:/ / www.mdpi.com/2071-105 0/13/5/2503/s1.

Author Contributions: Conceptualization, X.S. and R.L.; methodology, R.L., Y.C.; validation, R.L., Y.C., and F.Y.; formal analysis, X.S.; investigation, R.L., X.S., M.C.; resources, R.L.; data curation, X.S., and M.C.; writing-original draft preparation, X.S.; writing-review and editing, R.L.; supervision, R.L.; project administration, R.L.; funding acquisition, R.L. All authors have read and agreed to the published version of the manuscript.

Funding: This work was financially supported by the Program "Zero-Waste Agricultural Mulch Films for Crop in China" (2017YFE0121900), the Special Fund project for Marine Economic Development (six major marine industries) of Guangdong Province (2020, 059), and the Program of Science and Technology of Shenzhen (JCYJ20170818090224745).

Data Availability Statement: Not applicable.

Conflicts of Interest: The authors declare no conflict of interest.

\section{References}

1. Brito, P.; Prego, R.; Mil-Homens, M.; Caçador, I.; Caetano, M. Sources and distribution of yttrium and rare earth elements in surface sediments from Tagus estuary, Portugal. Sci. Total. Environ. 2018, 621, 317-325. [CrossRef] [PubMed]

2. Dushyantha, N.; Batapola, N.; Ilankoon, I.; Rohitha, S.; Premasiri, R.; Abeysinghe, B.; Ratnayake, N.; Dissanayake, K. The story of rare earth elements (REEs): Occurrences, global distribution, genesis, geology, mineralogy and global production. Ore Geol. Rev. 2020, 122, 103521. [CrossRef]

3. Ma, L.; Dang, D.H.; Wang, W.; Evans, R.D.; Wang, W.X. Rare earth elements in the Pearl River Delta of China: Potential impacts of the REE industry on water, suspended particles and oysters. Environ. Pollut. 2019, 244, 190-201. [CrossRef] [PubMed]

4. Squadrone, S.; Brizio, P.; Stella, C.; Mantia, M.; Battuello, M.; Nurra, N.; Sartor, R.M.; Orusa, R.; Robetto, S.; Brusa, F.; et al. Rare earth elements in marine and terrestrial matrices of Northwestern Italy: Implications for food safety and human health. Sci. Total. Environ. 2019, 660, 1383-1391. [CrossRef]

5. Bartolini, F.; Cimò, F.; Fusi, M.; Dahdouh-Guebas, F.; Lopes, G.P.; Cannicci, S. The effect of sewage discharge on the ecosystem engineering activities of two East African fiddler crab species: Consequences for mangrove ecosystem functioning. Mar. Environ. Res. 2011, 71, 53-61. [CrossRef] [PubMed]

6. Romero-Freire, A.; Joonas, E.; Muna, M.; Cossu-Leguille, C.; Vignati, D.; Giamberini, L. Assessment of the toxic effects of mixtures of three lanthanides (Ce, Gd, Lu) to aquatic biota. Sci. Total. Environ. 2019, 661, 276-284. [CrossRef] [PubMed]

7. Silva, M.M.V.G.; Lopes, S.P.; Gomes, E.C. Geochemistry and behavior of REE in stream sediments close to an old Sn-W mine, Ribeira, Northeast Portugal. Geochem. 2014, 74, 545-555. [CrossRef]

8. Herrmann, H.; Nolde, J.; Berger, S.; Heise, S. Aquatic ecotoxicity of lanthanum - A review and an attempt to derive water and sediment quality criteria. Ecotoxicol. Environ. Saf. 2016, 124, 213-238. [CrossRef]

9. Lavezzo, B.; Kinoshita, A.; Figueiredo, A.M.G.; Pinheiro, M.M.F.; Santana, W. Detection of rare-earth elements using fiddler crabs Leptuca leptodactyla (Crustacea: Ocypodidae) as bioindicators in mangroves on the coast of São Paulo, Brazil. Sci. Total. Environ. 2020, 738, 139787. [CrossRef]

10. Delgado, J.; Pérez-López, R.; Galván, L.; Nieto, J.M.; Boski, T. Enrichment of rare earth elements as environmental tracers of contamination by acid mine drainage in salt marshes: A new perspective. Mar. Pollut. Bull. 2012, 64, 1799-1808. [CrossRef]

11. Deng, H.; He, J.X.; Feng, D.; Zhao, Y.Y.; Sun, W.; Yu, H.M.; Ge, C.J. Microplastics pollution in mangrove ecosystems: A critical review of current knowledge and future directions. Sci. Total. Environ. 2021, 753, 142041. [CrossRef] [PubMed]

12. Brito, P.; Malvar, M.; Galinha, C.; Cacador, I.; Canario, J.; Araujo, F.; Raimundo, J. Yttrium and rare earth elements fractionation in salt marsh halophyte plants. Sci. Total Environ. 2018, 643, 1117-1126. [CrossRef] [PubMed] 
13. De Freitas, T.O.; Pedreira, R.M.; Hatje, V. Distribution and fractionation of rare earth elements in sediments and mangrove soil profiles across an estuarine gradient. Chemosphere 2021, 264, 128431. [CrossRef] [PubMed]

14. Wang, H.P.; Ji, Y.N.; Fu, X.N.; Zhao, Z.Z. Distribution and restriction factors of rare earth elements in sediments from the mangrove in Dongzhai Harbor, Hainan Island. Trop Geo. 2017, 37, 82-90.

15. Mandal, S.K.; Ray, R.; González, A.G.; Mavromatis, V.; Pokrovsky, O.S.; Jana, T.K. State of rare earth elements in the sediment and their bioaccumulation by mangroves: A case study in pristine islands of Indian Sundarban. Environ. Sci. Pollut. Res. 2019, 26, 9146-9160. [CrossRef] [PubMed]

16. Wu, J.; Lu, J.; Li, L.M.; Min, X.Y.; Zhang, Z.H.; Luo, Y.M. Distribution, pollution, and ecological risks of rare earth elements in soil of the northeastern Qinghai-Tibet Plateau. Hum. Ecol. Risk Assess. Int. J. 2018, 25, 1816-1831. [CrossRef]

17. Wang, H.P.; Zhao, Z.Z.; Fu, X.N. Source tracing of rare earth elements in sediments under mangrove inhabiting Dongzhai Harbor, Hainan Island. Trans. Oceanol. Limnol. 2018, 2, 74-79.

18. Gu, Y.G.; Gao, Y.P.; Huang, H.H.; Wu, F.X. First attempt to assess ecotoxicological risk of fifteen rare earth elements and their mixtures in sediments with diffusive gradients in thin films. Water Res. 2020, 185, 116254. [CrossRef] [PubMed]

19. Tu, W.; Hu, Z.W.; Li, L.F.; Cao, J.Z.; Jiang, J.C.; Li, Q.P.; Li, Q.Q. Portraying urban functional zones by coupling remote sensing imagery and human sensing data. Rem. Sens. 2018, 10, 141. [CrossRef]

20. Yang, X.; Fang, Z.; Yin, L.; Li, J.; Zhou, Y.; Lu, S. Understanding the spatial structure of urban commuting using mobile phone location data: A case study of Shenzhen, China. Sustainability 2018, 10, 1435. [CrossRef]

21. Cheng, H.D.; Lin, Q.H.; Yi, W.X.; Yang, Z.L.; Zhu, F. The distribution of rare earth elements (REE) in the Shenzhen Bay and Dapeng Bay recent sediments. Geochimica 1991, 3, 283-291.

22. Li, F.L.; Zeng, X.K.; Yang, J.D.; Zhou, K.; Zan, Q.J.; Lei, A.P.; Tam, N.F.Y. Contamination of polycyclic aromatic hydrocarbons (PAHs) in surface sediments and plants of mangrove swamps in Shenzhen, China. Mar. Pollut. Bull. 2014, 85, 590-596. [CrossRef]

23. Chai, M.W.; Li, R.L.; Ding, H.; Zan, Q.J. Occurrence and contamination of heavy metals in urban mangroves: A case study in Shenzhen, China. Chemosphere 2019, 219, 165-173. [CrossRef]

24. Chai, M.W.; Li, R.L.; Shi, C.; Shen, X.X.; Li, R.Y.; Zan, Q.J. Contamination of polybrominated diphenyl ethers (PBDEs) in urban mangroves of Southern China. Sci. Total Environ. 2019, 646, 390-399. [CrossRef]

25. Li, R.L.; Yu, L.Y.; Chai, M.W.; Wu, H.L.; Zhu, X.S. The distribution, characteristics and ecological risks of microplastics in the mangroves of Southern China. Sci. Total. Environ. 2020, 708, 135025. [CrossRef] [PubMed]

26. Yang, Q.; Lei, A.P.; Li, F.L.; Liu, L.N.; Zan, Q.J.; Shin, P.K.S.; Cheung, S.G.; Tam, N.F.Y. Structure and function of soil microbial community in artificially planted Sonneratia apetala and S. caseolaris forests at different stand ages in Shenzhen Bay, China. Mar. Pollut. Bull. 2014, 85, 754-763. [CrossRef]

27. Morgan, B.; Johnston, S.G.; Burton, E.D.; Hagan, R.E. Acidic drainage drives anomalous rare earth element signatures in inter-tidal mangrove sediments. Sci. Total Environ. 2016, 573, 831-840. [CrossRef]

28. Taylor, S.R.; McLennan, S.M. The Continental Crust: Its Composition and Evolution; Blackwell Scientific Publications: Palo Alto, CA, USA, 1985.

29. Xu, N.; Morgan, B.; Rate, A.W. From source to sink: Rare-earth elements trace the legacy of sulfuric dredge spoils on estuarine sediments. Sci. Total. Environ. 2018, 1537-1549. [CrossRef]

30. Kulaksiz, S.; Bau, M. Contrasting behavior of anthropogenic gadolinium and natural rare earth elements in estuaries and the gadolinium input into the North Sea. Earth Planet. Sci. Lett. 2007, 260, 361-371. [CrossRef]

31. Müller, G. Index of geopaccumulation in sediments of the Rhine River. GeoJournal. 1969, 2, 108-118.

32. Madiseh, S.D.; Savary, A.; Parham, H.; Sabzalizadeh, S. Determination of the level of contamination in Khuzestan coastal waters (Northern Persian Gulf) by using an ecological risk index. Environ. Monit. Assess. 2008, 159, 521-530. [CrossRef]

33. Bhuiyan, M.A.H.; Parvez, L.; Islam, M.A.; Dampare, S.B.; Suzuki, S. Heavy metal pollution of coral mine-affected agricultural soils in the northern part of Bangladesh. J. Hazard. Mater. 2010, 173, 384-392. [CrossRef]

34. Wu, J.; Duan, D.P.; Lu, J.; Luo, Y.M.; Wen, X.H.; Guo, X.Y.; Boman, B.J. Inorganic pollution around the Qinghai-Tibet Plateau: An overview of the current observations. Sci. Total. Environ. 2016, 550, 628-636. [CrossRef]

35. Wei, F.S.; Liu, T.L.; Teng, E.J.; Rui, K.S. Rare earth elements in Chinese soil. Chin. J. Environ. Sci. 1991, 12, 78-82.

36. Wang, Z.; Zhao, Y.C.; Luo, Y.F.; Zheng, C.L.; Bian, Y.; Zhang, G.Y. Document Knowledge Network. Available online: https: / / kns.cnki.net/kcms/detail/11.1895.X.20200922.1755.018.html (accessed on 23 January 2020).

37. Abrahim, G.M.S.; Parker, R.J. Assessment of heavy metal enrichment factors and the degree of contamination in marine sedi-ments from Tamaki Estuary, Auckland, New Zealand. Environ. Monit. Assess. 2008, 136, 227-238. [CrossRef]

38. Seshan, B.R.R.; Natesan, U.; Deepthi, K. Geochemical and statistical approach for evaluation of heavy metal pollution in core sediments in southeast coast of India. Int. J. Environ. Sci. Technol. 2010, 7, 291-306. [CrossRef]

39. Ćujić, M.; Dragović, S.; Đorđević, M.; Dragović, R.; Gajić, B. Environmental assessment of heavy metals around the largest coal fired power plant in Serbia. Catena 2016, 139, 44-52. [CrossRef]

40. Yu, K.; Duan. Y.H.; Liao, P.; Xie, L.; Li, Q.Q.; Ning, Z.G.; Liu, C.X. Watershed-scale distributions of heavy metals in the hyporheic zones of a heavily polluted Maozhou River watershed, southern China. Chemosphere 2020, 239, 124773. [CrossRef] [PubMed]

41. Tam, N.F.-Y.; Wong, Y.S. Variations of soil nutrient and organic matter content in a subtropical mangrove ecosystem. Water, Air, Soil Pollut. 1998, 103, 245-261. [CrossRef] 
42. Yan, H.; He, X.; Lei, Y.; Wang, Y.; Su, H.; Jiang, S. Land use-induced change in trophic state of Shenzhen Bay (South China) over the past half-century. Mar. Pollut. Bull. 2019, 145, 208-213. [CrossRef]

43. Shi, C.; Yu, L.Y.; Chai, M.W.; Niu, Z.Y.; Li, R.L. The distribution and risk of mercury in Shenzhen mangroves, representative urban mangroves affected by human activities in China. Mar. Pollut. Bull. 2020, 151, 110866. [CrossRef] [PubMed]

44. Sappal, S.M.; Ramanathan, A.L.; Ranjan, R.K.; Singh, G.; Kumar, A. Rare earth elements as biogeochemical indicators in man-grove ecosystems (Pichavaram, Tamilnadu, India). J. Sediment Res. 2014, 84, 781-791. [CrossRef]

45. Huang, H.B.; Lin, C.Q.; Yu, R.L.; Yan, Y.; Hu, G.R.; Wang, Q. Spatial distribution and source appointment of rare earth elements in paddy soils of Jiulong River Basin, Southeast China. J. Geochem. Explor. 2019, 200, 213-220. [CrossRef]

46. Shang, D.; Geissler, B.; Mew, M.; Satalkina, L.; Zenk, L.; Tulsidas, H.; Barker, L.; El-Yahyaoui, A.; Hussein, A.; Taha, M.; et al. Unconventional uranium in China's phosphate rock: Review and outlook. Renew. Sustain. Energy Rev. 2021, 140, 110740. [CrossRef]

47. Zhou, W.; Han, G.; Liu, M.; Song, C.; Li, X. Geochemical distribution characteristics of rare earth elements in different soil profiles in Mun river basin, Northeast Thailand. Sustainability 2020, 12, 457. [CrossRef]

48. Davranche, M.; Grau, G.; Dia, A.; Le Coz-Bouhnik, M.; Marsac, R.; Pédrot, M.; Pourret, O. Trace Elements in Waterlogged Soils and Sediments. In Rare Earth Elements in Wetlands; Rinklebe, J., Knox, A.S., Paller, M., Eds.; Taylor \& Francis Group: Abingdon, UK, 2017; pp. 135-162.

49. Bastakoti, U.; Bourgeois, C.; Marchand, C.; Alfaro, A.C. Urban-rural gradients in the distribution of trace metals in sediments within temperate mangroves (New Zealand). Mar. Pollut. Bull. 2019, 149, 110614. [CrossRef]

50. Chaillou, G.; Anschutz, P.; Lavaux, G.; Blanc, G. Rare earth elements in the modern sediments of the Bay of Biscay (France). Mar. Chem. 2006, 100, 39-52. [CrossRef]

51. Pérez-López, R.; Delgado, J.; Nieto, J.M.; Márquez-García, B. Rare earth element geochemistry of sulphide weathering in the São Domingos mine area (Iberian Pyrite Belt): A proxy for fluid-rock interaction and ancient mining pollution. Chem. Geol. 2010, 276, 29-40. [CrossRef]

52. Davranche, M.; Grybos, M.; Gruau, G.; Pédrot, M.; Dia, A.; Marsac, R. Rare earth element patterns: A tool for identifying trace metal sources during wetland soil reduction. Chem. Geol. 2011, 284, 127-137. [CrossRef]

53. Hannigan, R.; Dorval, E.; Jones, C. The rare earth element chemistry of estuarine surface sediments in the Chesapeake Bay. Chem. Geol. 2010, 272, 20-30. [CrossRef]

54. Zhang, R.F.; Yan, C.L.; Liu, J.C. Effect of mangroves on the horizontal and vertical distributions of rare earth elements in sedi-ments of the Zhangjiang Estuary in Fujian Province, Southeastern China. J. Coastal Res. 2013, 29, 1341-1350. [CrossRef]

55. Morgan, B.; Rate, A.W.; Burton, E.D.; Smirk, M.N. Enrichment and fraction of rare earth elements in FeS- and organic-rich estuarine sediments receiving acid sulfate soil drainage. Chem. Geol. 2012, 308-309, 60-73. [CrossRef]

56. Xu, C.; Kynický, J.; Smith, M.P.; Kopriva, A.; Brtnický, M.; Urubek, T.; Yang, Y.H.; Zhao, Z.; He, C.; Song, W.L. Origin of heavy rare earth mineralization in South China. Nat. Commun. 2017, 8, 14598. [CrossRef]

57. Lawrence, M.G.; Jupiter, S.D.; Kamber, B.S. Aquatic geochemistry of the rare earth elements and yttrium in the Pioneer River catchment, Australia. Mar. Freshw. Res. 2006, 57, 725-736. [CrossRef]

58. De Caritat, P.; Cooper, M. National Geochemical Survey of Australia: The Geochemical Atlas of Australia; Geoscience Australia: Canberra, Australia, 2011; Volume 2, p. 557.

59. Pagano, G.; Guida, M.; Tommasi, F.; Oral, R. Health effects and toxicity mechanisms of rare earth elements-Knowledge gaps and research prospects. Ecotoxicol. Environ. Saf. 2015, 115, 40-48. [CrossRef] [PubMed]

60. Fiket, Ž.; Mikac, N.; Kniewald, G.; Željka, F.; Nevenka, M.; Goran, K. Influence of the geological setting on the REE geochemistry of estuarine sediments: A case study of the Zrmanja River estuary (eastern Adriatic coast). J. Geochem. Explor. 2017, 182, 70-79. [CrossRef] 